\title{
Water Treatment Biology Teaching Reform Based on Engineering Education Certification
}

\author{
Bo Guo*, Yaqing Li, Sufang Wang \\ College of Environmental Science and Engineering, \\ Taiyuan University of Technology \\ Taiyuan, Shanxi, 030024, P.R. China
}

\begin{abstract}
The course teaching reforms of water treatment biology, based on engineering education certification, aims at cultivating the comprehensive abilities of students to analyze and solve the complex problems in water supply and sewerage science and engineering. The reforms were performed by optimizing and integrating teaching contents, establishing of a multi-level training system for innovation practice ability and guiding students to use the integrated knowledge in the training. The practice abilities and innovation consciousness of students have been evidently improved. Meanwhile, the students' abilities of exchange and cooperation with each other can be developed well.
\end{abstract}

Keywords-engineering education; water treatment biology; teaching reform; Certification

\section{INTRODUCTION}

Engineering education certification is an important prerequisite for the international mutual recognition system of engineering degrees and engineers. Since the 1980s, some countries initiated the international mutual recognition system for engineering education and engineers, and signed Washington Accord (WA). China became a full member of Washington Accord on June 2, 2016. Bachelor's degrees of engineering majors in mainland China certified by China Engineering Education Accreditation Association (CEEAA), will be recognized by the United States, the United Kingdom, Australia and other official members of WA. It is of great significance for China's engineering to cope with international competition.

By the end of 2017, a total of 11 majors in Taiyuan University of Technology had passed the engineering education certification according to the issue by Ministry of Education of China on June 12, 2018.

Engineering education certification is of the certification of a major, including various supporting curriculums about the major. The curriculums construction provides a guarantee for the construction and development of the major. So it is very necessary to reform the curriculum teaching guided by engineering education certification [1-2]. The course, water treatment biology, is one of the core courses for the major of water supply and drainage, and also one of the important basic courses. This course combines general biology, general microbiology, environmental microbiology and water quality engineering to meet the needs of water treatment and environmental water quality purification [3]. Based on the knowledge of (micro) biology, this course introduces the mechanism and rules in water quality treatment and water purification to solve complicated engineering problems.

In this paper, the course teaching reforms of water treatment biology based on engineering education certification, have been made in the teaching contents, the cultivation system of innovative practical ability and the assessing ways to aim at the main problems and deficiencies existing in the current course teaching.

\section{OPTIMIZING THE TEACHING CONTENTS ACCORDING TO THE COURSE OBJECTIVES}

The objectives of engineering education certification are determined by graduation requirements, curriculum system and curriculum characteristics. The course, water treatment biology, supports three index points of the graduation requirements for water supply and drainage:

1) Solving the complicated scientific and engineering problems of water supply and drainage with professional basic knowledge;

2) Being able to identify, refine, define and express complicated problems of water supply and drainage;

3) Having the abilities to select necessary experimental methods, design experimental schemes, operate experimental devices correctly and carry out related experiments safely for complicated problems of water supply and drainage science and engineering.

According to the three points to determinate the curriculum goals: students are required to analyze and explain correctly the phenomenon of natural and artificial environment, understand and master the application of the knowledge of biology in water supply and drainage engineering, have a solid foundation to solve the complicated problems in water supply and drainage science and engineering.

The course, water treatment biology, covers a wide range of knowledge and lasts only for 48 teaching hours including 32 class teaching hours and 12 experiment teaching hours. So it is necessary to integrate and optimize the teaching contents in order to achieve the teaching objectives with fewer classes.

\section{A. Optimizing and integrating classroom teaching contents}

At present, the main problems in classroom teaching are lack of correlation with relevant courses, Lack of communication within the teaching team resulting in repeated teaching of overlapping contents. Aiming to solve above 
problems, the classroom teaching contents are optimized and integrated, and the teaching hours of each chapter is redistributed.

\section{1) Highlighting the role of microorganisms in water} treatment

The course mainly introduces the microorganisms related to water treatment, including prokaryotes (bacteria, actinomycetes and cyanobacteria) and eukaryotes (fungi, algae, protozoa and micrometazoa). The important role of zoogloea (the main form of bacteria in activated sludge) in water treatment (adsorption, degradation of organic matter and promotion of sedimentation) and protozoa and micromezoa as indicators of sewage treatment are emphasized. While some microorganisms with less use in water treatment, such as mycoplasma, rickettsia and chlamydia, will give no explanation in the class but assigned as students' self-study contents.

2) Correlating with relevant courses and avoiding repeated teaching contents between courses.

It is important to associate the teaching contents with related courses in our teaching. For example, the chapter "the main microorganisms in the wastewater treatment system" involves the contents of the sewage biological treatment methods which are related to the course "water quality engineering". In our teaching, typical aerobic and anaerobic biological treatment systems combined with related knowledge of microorganisms are explained to help students better understand the mechanism of the microbes. In addition, contents that intersect between courses is briefly stated or omitted to avoid repetition. For example, biochemistry involves more detailed knowledge of "enzymes", which is only briefly introduced in this course.

3) Paying attention to the combination of theory and practice and adding contents on the latest scientific research trends

Microorganisms are so tiny that they must be observed with an optical microscope or even an electron microscope. While microbes are ubiquitous and act on the environment all the time. A large number of pictures about microorganisms are collected to help students form a perceptual understanding of kinds of microorganisms. At the same time, various phenomena related to microorganisms in the natural and artificial environment are explained to make students understand relevant knowledge and improve their comprehensive quality. Hot issues and frontier technologies are introduced, such as genetic engineering problems and the techniques of sludge reduction, harmless and resource.

\section{B. Exploratory reform of experimental teaching}

Water treatment biology is a typical practical subject, and the experimental teaching plays an irreplaceable role in cultivating students' practical abilities, independent analysis abilities and problem solving abilities. In the teaching of this course, experimental teaching takes up 16 class hours, with one third of the total class hours. The main problems existing in the original experimental teaching were as follows: a) The arrangement of experimental contents was not reasonably enough and most of them were the type of verification experiments; b) Due to the limited class hours, the consistency of the experiment cannot be guaranteed and it is difficult to complete comprehensive experiments and design experiments; c) Students lack basic experimental skills training.

The integration of traditional experiments with the reduction of confirmatory experiments and increase of comprehensive and designed experimental contents

The experiments of water treatment biology involving basic operation technologies, which is essential for the water treatment biology studies, include the contents as follows: the use of the microscope; microorganism morphology observation counting the microbe number; the preparation and sterilization of culture medium; the separation of microorganism; the observation of colony morphology and dyeing technology, etc. These experiments aim at training the basic skills of students. The experiments are arranged according to the development of students' cognitive level and abilities and are effectively integrated [4-6].

Considering the limitation of experimental hours in the course, the repetitive experiment content should be reduced as much as possible on the premise of meeting the basic skills training. The traditional confirmatory experiments should be transformed into comprehensive ones. For example, the experimental contents, "the use of the microscope", "microorganism morphology observation" and "counting the microbe number" are integrated and designed to a comprehensive experiment. In the new experiment, microscopic samples are observed first to let students master the use of microscope and form perceptions of typical microbial morphologies. Then students should compare the variation of microbial species and quantities of sludge samples, which are collected from different training stages or in the process of water treatment systems, to understand the effects of protozoa and tiny metazoan as a biological indicator in the sewage treatment. For another example, the traditional experiments, "the preparation and sterilization of culture medium"; "the separation of microorganism"; "the observation of colony morphology and dyeing technology" could be integrated and transformed to a comprehensive one. Firstly, various sludge or sewage samples are collected according to the purposes of design; and then culture mediums are prepared and sterilization for the use of the separation of microorganism; the pure species are separated from sludge or sewage samples (several separation technologies can be tried) and cultivated at constant temperature after 24-48 hours; and then colony morphologies in culture dishes are observed; gram characteristics identification of bacterial colonies can be conducted by staining technology. Thus, the integrated experiments could reduce the repetitive experimental contents and also help students to form an overall and systematic view. At the same time, a lot of design elements are added into the comprehensive experiment, such as comparing the species and quantity of microorganisms in different samples; identifying the gram characteristics of pure strains separated from different samples, etc., which is conducive to improving the scientific research qualities of students and enhancing their interest and abilities of independent exploration. 


\section{Introduction and application of complicated problems of water supply and drainage science and engineering in teaching}

As mentioned above, three index points of professional graduation requirements for water supply and drainage are propped up by the course "water treatment biology". It is the core of the three index points to solve the complicated problems of water supply and drainage. So the introduction of the complicated problems and the related knowledge for solving the problems are emphasized in the course teaching. For example, the chapter "the main microorganisms in the wastewater treatment system" involves important contents of the sewage biological treatment methods. In practice, the treatment and disposal of sludge in sewage biological treatment system have been a complex problem in urban sewage treatment plants. In-class teaching, the formation of complex engineering problems would be interpreted combining the basic knowledge and principles of water treatment biology and the latest developments are also introduced. The principles of sludge disposal are reduction, harmless and resource. The core of sludge reduction is dehydration. Sludge has a high moisture content but is dehydrated difficultly due to the existence of intracellular water. At present, filter pressing, centrifugation and other physical methods can only remove the interstitial water of sludge. In order to achieve the ideal effects of dehydration, the possible solution is to break the wall of cells. Therefore, the latest technologies and methods of sludge dewatering and the latest research and development of sludge harmless and resource utilization are introduced in-class teaching. For another example, new technologies of biological nitrogen removal, such as short-range nitrification and denitrification, are introduced on the basis of the traditional process of aerobic nitrification and anoxic denitrification so as to expand the professional vision of students and lay a foundation for solving complex problems.

\section{ESTABLISHING A MULTI-LEVEL TRAINING SYSTEM FOR INNOVATIVE PRACTICAL ABILITY AND TEAMWORK SPIRIT OF STUDENTS}

It is the trend of teaching reform to establish a multi-level practical training system. It will make practice teaching to be the multi-level and the diversified direction system and the teaching effects will be greatly improved and make students conform to the social development request.

\section{A. A multi-level training system for innovative abilities}

The goal of engineering education in universities is to cultivate high-quality innovative talents. The teaching of water treatment biology, should not only make students consolidate the course of basic theoretical knowledge and master the basic experimental operation skills, should pay more attention to students' experience and understanding of the discipline, and train the students to integrate theory with practice, find and solve problem, and cultivate their preliminary scientific research ability. Following the law of students' cognitive development, the teaching should let students gradually experience, comprehend, improve and expand their cognition in the field of practice, so as to form their own unique professional thinking and possess certain scientific research quality and innovation ability. To this end, a multi-level innovative practical ability cultivation system has been established based on in-class experiment teaching, combined with extracurricular open experiment project and innovation and entrepreneurship training program for college students.

The open experiment project for college students would be implemented as follows: 1) The teacher would give the assignment of the experiment project; 2) Above 2 projectrelated literature reviews would be explained; 3 ) The students would be guided to consult literature and summarize research methods; 4) Students would discuss and make research plans; 5) Teachers would guide students to determine the experimental scheme; 6) Carry out experimental research; 7) Medium-term inspection; 8) Data analysis and summary.

The innovation and entrepreneurship training programs for college students are often combined with teachers' scientific research projects. The project leader is a student. The training program emphasizes student-centered interaction between students and teachers. The autonomy and innovation of students could be embodied. The program would be carried out as follows: 1) Students choose research directions according to teachers' scientific research projects;2) Teachers guide students to consult relevant literature; 4) Students discuss and formulate research routes and experimental schemes; 5) Guide teachers check the feasibility of the plan; 6) carry out experimental research; 7) medium-term inspection;8) data analysis and summary.

\section{B. Cultivating students' team spirit during the practice}

According to article 9, 10 and 11 of the general standard of engineering education certification, Graduates should have team spirit, communication, international vision, organization and management, social competition and cooperation ability. Both in-class experiments and after-class practical projects are conducive to cultivating the spirit of communication and cooperation among students.

Most of the in-class experiments in water treatment biology have the characteristics of large contents and long time consuming, especially the integrated comprehensive experiments. In the case of limited laboratory hours, the usual measures are the division of labor and data sharing. On the basis of ensuring students to master basic operational skills, students are divided into groups according to the specific contents of the experiment. Different groups will carry out experiments at different conditions or factors, and the experimental results of each group will be shared with each other. In this way, on the one hand, comprehensive or designed experiment contents would be added to expand the professional outlook, and meanwhile, it would promote the exchange and communication between students and cultivate the spirit of cooperation each other. For example, in the experiment "Observation of microbial morphology in activated sludge", students are divided into several groups and each group select different sludge samples, which collected from different training periods or hydraulic structures. Microbes in the samples would be observed under the microscope and typical photos or videos would be taken and sent to professional learning groups. The species and quantity of microorganisms in the sludge samples would be compared and the changes of microbial species and quantity would be understood the role of 
protozoa and miniature metazoan as the biological indicator in microscopy for sewage disposal systems.

\section{CONTINUOUS IMPROVEMENT OF ASSESSMENT AND EVALUATION}

Continuous improvement is not only the core concept of engineering education certification but also an important feature of it. The course assessment is an important part in the course teaching, and also the most important basis for teachers' teaching quality and students' knowledge mastery $[7,8]$. In the past, the course assessment was mainly based on the final examination of the class, and the usual performance was only based on the attendance rate, which was not conducive to time finding out the students' mastery of knowledge and making corresponding adjustments or improvements. At present, the total score of the course is composed of the classroom score (70\%) and practice score (30\%), among which the classroom score includes the classroom performance (10\%), homework (10\%) and final examination score (80\%). The form of the final exam is a closed one. Questions in the examination should be the combination of subjective and objective ones and covering course knowledge. Knowledge and ability of students should be assessed in the examination. It is strengthened to assess basic knowledge for solving complex problems of water supply and drainage. Test questions corresponding to the simulation practice would be increased to check the students' ability to analyze and resolve problems.

At the end of the course, it is necessary to evaluate and analyze the degree of achievement of the course. The analysis report mainly includes the following aspects:

1) The rationality analysis of the examination, including the difficulty, the distribution of test scores and the coverage of test questions, whether or not meet the requirements of the course syllabus;

2) The analysis of the course conformity assessment: whether corresponding to the index points of graduation requirements; whether the course syllabus reflects the index points, whether the index points are easy to assess and evaluate; whether the results of assessment and evaluation reflect the degree of difficulty; Whether the score setting is reasonable; Whether the knowledgeability points are fully covered; whether the strictness of assessment, the evaluate process data and results are for improvement;

3) The evaluation results, of course, would be formed according to the calculation results of course completion degree and evaluation value, and analyzing the course teaching objectives, ways to achieve, evaluation basis and mode;

4) Existing problems and continuous improvement, finding problems from the achievement evaluation results, and proposing methods or measures for continuous improvement.

\section{CONCLUSION}

On the background of engineering education certification, the curriculum teaching reform of water treatment biology based on students as the center, aims at cultivating the comprehensive abilities of students to analyze and solve the complex problems in water supply and sewerage science and engineering, The teaching reforms have been performed by optimizing and integrating classroom and practical teaching contents, establishing a multi-level system of innovative practice ability, and continual improvement of the teaching and evaluation mode. The practice abilities and innovation consciousness of students have been evidently improved. Meanwhile, the students' abilities of exchange and cooperation with each other can be developed well.

\section{REFERENCES}

[1] TY. Li, Training innovation and practice ability of college students under the background of engineering certification [J]. Henan Chemical Industry. 2014, pp. 59-61. (In Chinese)

[2] W. Zhao, Y. Wang, Research on experimental teaching reform of fine chemical engineering under the background of engineering certification [J]. Journal of Jilin University of Education (second half). 2015, pp. 7980. (In Chinese)

[3] X. Gu, H. Hu, X. Wen, et al. Water treatment biology [M]. Beijing: China Architecture \& Building Press, 2006.

[4] B. He, Discussion on Water Treatment Biology Experimental Teaching [J]. Research and exploration in laboratory. 2011, vol. 30, pp. 306-308. (In Chinese)

[5] M. Ma, Fuzzy set analysis in psychology [M]. Guiyang: Guizhou Science and Technology Press, 1994. (In Chinese)

[6] X. Wang, C. Jia, X. Wang, et al. Building up a new teaching system in physical chemistry [J] Experimental Technology and Management. 2008 vol. 25, pp. 20-23. (In Chinese)

[7] L. Zhao, C. Yue, N. Ma. Discussion on teaching reform of water treatment biology under the background of transformation and development [J]. Journal of Nanyang Normal University. 2018, vol. 17, pp. 62-65.

[8] Y. Hu, X. Zhang. A preliminary study on the reform of the process assessment method with ability as the core. Journal of Chongqing Electric Power Technical College. 2012, pp. 8-10. 